\title{
The Influence of Cortical Maturation on the BOLD Response: An fMRI Study of Visual Cortex in Children
}

\author{
VALENTINE L. MARCAR, ANDREA E. STRÄSSLE, THOMAS LOENNEKER, \\ UWE SCHWARZ, AND ERNST MARTIN
}

Institute of Psychology, Neuropsychology [V.L.M.], University of Zürich, CH-8032 Zürich, Switzerland, Department of Diagnostic Imaging, Neuroradiology and Magnetic Resonance Imaging [A.E.S., T.L.,

E.M.], University Children's Hospital Zürich, CH-8032 Zürich, Switzerland, Department of Anaesthetics [U.S.], University Hospital Zürich, CH-8091 Zürich, Switzerland

\begin{tabular}{|c|c|}
\hline \multicolumn{2}{|c|}{ ABSTRACT } \\
\hline $\begin{array}{l}\text { We performed blood oxygenation level-dependent (BOLD) } \\
\text { functional MR imaging in } 11 \text { children younger than } 5 \text { y of age } \\
\text { and } 10 \text { children older than } 5 \text { y of age. All but five of the children } \\
\text { in the older age group were tested under light anesthesia. We } \\
\text { examined the cerebral oxidative metabolism }\left(\mathrm{CMRO}_{2}\right) \text { associ- } \\
\text { ated with the processing of a flashed and a reversing checker- } \\
\text { board stimulus. These stimuli had been shown in a previous } \\
\text { study to induce identical vascular responses. The reversing } \\
\text { checkerboard activated twice the neuronal population of the } \\
\text { flashed checkerboard, doubling the CMRO }{ }_{2} \text { associated with it. } \\
\text { We compared the extent of activation for the positive BOLD } \\
\text { response and found that it did not differ between the different age } \\
\text { groups. We estimated the oxidative metabolism by examining the } \\
\text { change in the local deoxyhemoglobin (HbR) concentration using } \\
\Delta \mathrm{R} 2 * \text { Because both stimuli induced the same vascular response, } \\
\text { any increase in oxygen requirement would have to be met by the } \\
\text { identical blood volume. Increasing CMRO } \mathrm{C}_{2} \text { will therefore result } \\
\text { in an increase in the oxygen extraction fraction (OEF), which } \\
\text { raises the local HbR concentration. In the younger children, both } \\
\text { checkerboard stimuli produced identical, high HbR concentra- } \\
\text { tions. In the older children, the HbR concentration to the flashed }\end{array}$ & $\begin{array}{l}\text { stimulus was significantly lower than to the reversing stimulus. } \\
\text { We conclude that, for identical stimuli, the oxidative energy } \\
\text { requirement associated with the cortical processing is higher in } \\
\text { young children than in older children because the presence of } \\
\text { superfluous synaptic connections in the immature visual system } \\
\text { activates a larger neuronal population. (Pediatr Res 56: 967-974, } \\
\text { 2004) } \\
\text { Abbreviations } \\
\text { BOLD, blood oxygenation level dependent } \\
\text { CBF, cerebral blood flow } \\
\text { CMRO } \\
\text { fMRI, cerebral metabolic rate of oxygen consumption } \\
\text { HbR, deoxyhemoglobin } \\
\text { MAC, mean alveolar concentration } \\
\text { MRI, magnetic resonance imaging } \\
\text { PET, positron emission tomography } \\
\text { OEF, oxygen extraction fraction } \\
\text { DR2*, change in relaxivity } \\
\text { TE, echo time } \\
\text { TR, repetition time }\end{array}$ \\
\hline
\end{tabular}

Humans rely on vision more than on any other of our senses. Vision is used to form our first social bonds in the immediate months after birth (1). At this age, visually guided behavior is based on processing occurring in subcortical structures such as the thalamus and the superior colliculus. Visual cortex does not make a functional contribution until the second month after birth (2,3). This observation implies that visual perception is

Received June 26, 2003; accepted April 8, 2004.

Correspondence: Valentine L. Marcar, D.Phil., University of Zürich, Institute of Psychology, Neuropsychology, Treichlerstrasse 10, CH-8032 Zürich, Switzerland, e-mail: v.marcar@psychologie.unizh.ch

Supported by a grant from the Swiss National Foundation for Scientific Research (SNF: 31-59363.99) and a grant from the Hartmann-Müller Foundation.

DOI: 10.1203/01.PDR.0000145296.24669.A5 served by two systems, a subcortical and a cortical system. The former is genetically determined whereas the latter is guided by experience. Visual pursuit or fixating appear to be fully developed at birth (4), whereas visual acuity and binocular vision improve within the first month of life independent of experience (5). This suggests that, even within the cortical, visual system, some mechanisms may be under genetic control whereas others are influenced by experience. This is reflected in the fact that the parvocellular system subserving color vision develops much more slowly than the magnocellular system used for perceiving movement $(6,7)$.

At the time of its discovery, striate cortex was thought to be all that was necessary for visual perception (8). The discovery of the extrastriate visual areas in the primate visual system 
increased our appreciation of its complexity. These extrastriate cortical visual areas currently number 30 in the monkey, a number that is expected to be exceeded in humans $(9,10)$. The complex interaction of the numerous brain regions involved in visual processing have led to the suggestion that the development of the visual system occurs in discrete steps with different parts of the system maturing at different times $(2,3)$.

Functional MRI provides a noninvasive means of visualizing neuronal activation underlying perceptual and cognitive processes and so can be used repeatedly and safely on children. Functional MRI has already been used successfully to investigate linguistic development (11-13), motor development $(14,15)$, and visual development in children (16-21). Still, special care has to be taken when it comes to interpreting the results of fMRI measurements on infants and children. The most important issues dealing with the special needs associated with fMRI measurements involving young children are summarized in the review article of Gaillard and colleagues (22).

These authors identified two alternative hypotheses of how the BOLD response of children could differ from that of adults. The immature nervous system could generate a more diffuse activation pattern or inefficient neuronal processing would be associated with an elevated metabolic cost. The first hypothesis suggests a larger extent of activation of the BOLD response in young children, whereas the alternative hypothesis suggests a higher rise in the $\mathrm{HbR}$ concentration and a smaller BOLD signal amplitude.

By studying the human visual system, we expect to gain insight into the changes in neuronal processing resulting from cortical maturation. We chose to perform our study on the visual cortex because much is known about its anatomical and functional organization.

The BOLD signal is linked to the vascular response arising from a neuronal challenge. To make any meaningful agerelated comparison of the BOLD signal it is important to be certain that the vascular response at different ages is comparable. A number of studies have reported that the hemodynamic response to a neuronal challenge in children younger than $5 \mathrm{y}$ of age and children older than $5 \mathrm{y}$ of age is identical $(15,23,24)$. We tested these alternative hypotheses using a modified version of the flashed and reversing stimulus paradigm used by Fox and Raichle (25). We successfully used this stimulus paradigm in adults to investigate the influence of doubling the OEF on the BOLD signal (26). Increasing the OEF increases the local HbR concentration, which in turn reduces the BOLD signal amplitude (27-31).

We hypothesized that a more diffuse neuronal activation to our stimuli would lead to a larger extent of activation in the younger children. If the neuronal processing in young children were less energy efficient, we would expect the measured BOLD signal amplitude to be lower in young children compared with older children. By comparing the BOLD response of visual cortex to the flashed and the reversing checkerboard stimulus in young and older children, we were in a position to gain an insight into the way maturational changes influence neuronal processing.

\section{MATERIALS AND METHODS}

Subjects. The subjects were 21 children aged between 3 mo and $12 \mathrm{y}$. We performed functional MR measurements on children in two age groups: children up to $5 \mathrm{y}$ of age $(n=11$; males: 3 females: 8$)$ and those older than 5 y of age $(n=10$; males: 5, females: 5). This division corresponded to the ratio between CNS to body mass reaching a peak at $5 \mathrm{y}$ of age, and the peak rate of cognitive development (32). All but half the children of the oldest age group were measured under anesthesia. The children measured under anesthesia were measured as part of a diagnostic MR imaging session that had to be performed under anesthesia because clinical indications necessitated it. Because these children usually suffered from or were suspected of a medical condition warranting a diagnostic MR, it was important to set strict inclusion and exclusion criteria. We excluded children with metabolic anomalies, micro-, macro-, or hydrencephaly, children having suffered from hypoxic asphyxia, children with abnormalities of the visual system or children with a tumour located in the cortex lying posterior to the central sulcus. Table 1 shows the different clinical indicators of the children measured under anesthesia. The study was approved by the hospital's ethics committee and informed consent from the child and at least one parent or guardian was obtained.

Anesthetic management. All anesthetic procedures were carried out by the institute's anesthetic team. The institutional guidelines relating to the performing of MR imaging under anesthesia were followed at all times. Each patient was administered midazolam (Dormicum; $0.5 \mathrm{mg} / \mathrm{kg}$, maximum dose 10 $\mathrm{mg}$ ) orally. This is a short-acting sedative and is used routinely to prepare patients for anesthesia. Tracheal intubation followed. The muscle relaxant pancuronium bromide (Pavulon, $0.1 \mathrm{mg} / \mathrm{kg}$ ) was administered. Breathing and anesthesia was thereafter controlled by a mechanical ventilator. Throughout the entire MR session, all vital signs, including rectal body temperature, respiratory rate, heart rate, blood pressure, blood oxygen saturation, and expiratory $\mathrm{CO}_{2}$, were constantly monitored by the anesthetic team. Expiratory $\mathrm{CO}_{2}$ levels were kept between $4.8 \%$ and $6.0 \%$.

Table 1. Clinical indicators of children measured under anesthesia

\begin{tabular}{cl}
\hline Patient no. & \multicolumn{1}{c}{ Clinical indicator } \\
\hline 01 & Cranial fracture \\
02 & Spinal MR \\
03 & Tumor in extremity \\
04 & Spinal MR \\
05 & Tumor in medulla \\
Y1 & Reported seizure with normal MR \\
Y2 & Reported seizure with normal MR \\
Y3 & Deafness with normal MR \\
Y4 & Physically small but normal MR \\
Y5 & Cranial surgery \\
Y6 & Reported seizure with normal MR \\
Y7 & Temporal lobe dysplasia \\
Y8 & "Protruiso bulbi" with normal MR \\
Y9 & Temporary loss of vision with normal MR \\
Y10 & Herpes infection \\
Y11 & Morbus Leigh \\
\hline
\end{tabular}


The depth of anesthesia is measured using the MAC. One MAC is defined as the concentration of a specific anesthetic agent at which half of the patients still respond to a noxious stimulus (e.g. surgical incision) (33). We performed our fMRI measurements with an anesthetic level of 0.5 MAC using the anesthetic agent Sevoflurane in an oxygen-air mixture. This level of anesthesia is considered light (33-35). In those children measured under anesthesia, the eyelids were kept open using titanium eyelid retractors. Before applying the lid retractors, a short-term, local analgesic agent (Alcaine, Alcon Pharmaceuticals, Mumbai, India) was administered to the eye. This agent has no influence on the pupil or the lens. The conjunctiva and cornea were protected using a clear gel (Viscotears, Novartis Ophthalmics AG, Basel, Switzerland). We ensured that the gel sealed the eye and that it set forming an even surface so as to minimize optical distortion of our image.

We waited until the end-tidal, expiratory concentration of sevoflurane corresponded to 0.5 MAC before commencing our functional MRI measurements. In the time required for the anesthesia level to stabilize at $0.5 \mathrm{MAC}$, a single diagnostic MRI measurement was performed so as not to unduly delay the examination of the child. After the anesthetist signaled that the level of anesthesia was stable at 0.5 MAC, the functional measurements commenced. The functional MR measurements did not exceed $15 \mathrm{~min}$. At the end of the functional MR measurements, the eyelid retractors were removed and the protective gel washed out. The eyes were then taped shut, as is customary for the institute when diagnostic MR imaging is being performed under anesthesia. The children that were tested awake were instructed to keep their eyes in the middle of the radial checkerboard and avoid large eye movements.

Apparatus. Measurements were performed on a 2 Tesla Bruker Tomikon S200 whole-body scanner (Bruker, Medical, Faellanden, Switzerland) using a modified surface coil operated in cross-coil mode. This coil was modified by affixing a surface-coated mirror to it in such a way that an image projected onto a translucent screen at the back of the magnet could be reflected on to the subject's eyes. The coil was positioned so that it was most sensitive to signals from the occipital lobe. Inspecting the images in Figure 1 reveals inhomogeneities in the anterior part of the brain. These are the result of the signal loss from the surface coil. This was compensated for by high sensitivity in the region of the visual cortex. Functional imaging was performed using a gradient echo and an echo planar imaging sequence with the following parameters: $\mathrm{TR}=2000 \mathrm{~ms}, \mathrm{TE}_{\text {effective }}=58 \mathrm{~ms}$, spectral width $=100 \mathrm{kHz}$, and a tip angle $=90^{\circ}$. We used a fat suppression pulse with a $350 \mathrm{~Hz}$ bandwidth. A package of 14 slices with a thickness of $4.5 \mathrm{~mm}$ and a gap of $1 \mathrm{~mm}$ were placed horizontally through the calcarine sulcus, so that the lowest slice coincided with the base of the occipital lobe. The field of view measured $25 \times 25 \mathrm{~cm}$ with a matrix size of $128 \times 64$ pixels, resulting in a spatial resolution of $2.0 \times 4.1 \mathrm{~mm}$. The echo planar images were then reconstructed to a matrix size of 128 $\times 128$ elements, including zero filling.

Stimuli. Our stimuli were a flashed and a reversing, radial checkerboard. Each checkerboard subtended a visual angle of $36^{\circ} \times 36^{\circ}$ at a viewing distance of $1.13 \mathrm{~m}$. The white and black elements of a checkerboard were equal in area. The reversing checkerboard was generated by reversing the contrast of the white elements only. The reversing checkerboard was generated by reversing the contrast of all elements (Fig. 1). We used a high luminance contrast (black and white) and a high chromatic contrast (red and blue) checkerboard stimuli. The luminance of the stimulus elements was measured using a luminance meter (Minolta LS 110; Konica Minolta, Tokyo, Japan). The luminance of the white elements was $144 \mathrm{~cd} / \mathrm{m}^{2}$, that of the black background was $0.4 \mathrm{~cd} / \mathrm{m}^{2}$. The luminance contrast ratio was $365: 1$. The luminance of the blue elements was 5.4 $\mathrm{cd} / \mathrm{m}^{2}$ whereas that of the red background was $29.3 \mathrm{~cd} / \mathrm{m}^{2}$. The luminance contrast ratio was 5.5:1.

We reversed the contrast twice per second. This is slower than the frequency used in other studies. In adults, a temporal frequency of $8 \mathrm{~Hz}$ leads to the largest CBF response $(25,36-$ 38), whereas the maximum increase in $\mathrm{CMRO}_{2}$ has been observed at $4 \mathrm{~Hz}(25,36-39)$. Our reason for choosing this frequency is that the lower temporal and spatial frequencies are perceived better by the immature visual system $(5,40-44)$.
Luminance Contrast

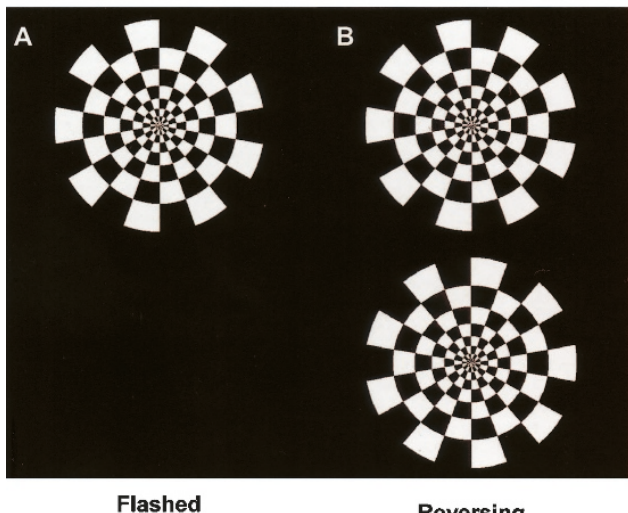

C
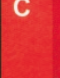

\section{Chromatic Contrast}

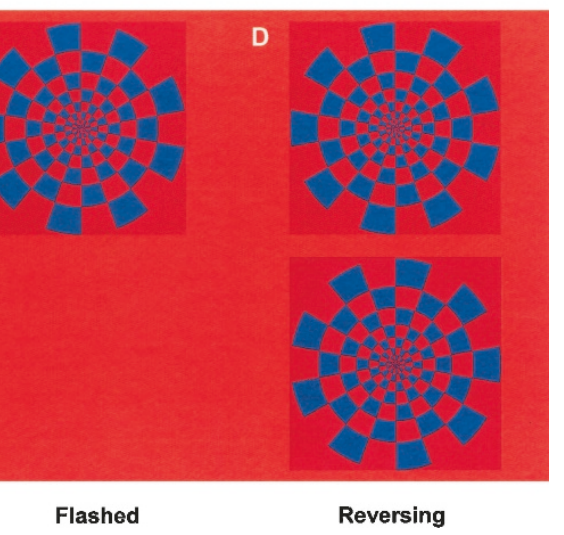

Figure 1. Luminance contrast version $(A, B)$ and chromatic contrast version $(C, D)$ of the flashed and reversing checkerboard stimulus pair. The two images used to generate the stimuli are shown in the top and bottom of each figure. The flashed checkerboard was alternated with an image of the background ( $A$, $C$ ) and the reversing checkerboard was alternated with a checkerboard where the luminance contrast of all elements was inverted $(B, D)$. 
Procedure. Each measurement was preceded by 10 dummy scans, which were immediately discarded and served only to bring the spin system into a steady state. The actual measurements started with 10 control scans $(20 \mathrm{~s})$, during which the subject viewed a static checkerboard. Ten stimulation scans (20 s) followed, during which either the flashed or the reversing checkerboard was presented. This cycle of control and stimulation period was repeated five times. The order in which the stimuli were presented was randomized between subjects.

Data analysis. We used the commercial package MEDx 3.4 (Sensor Systems, Sterling, VA) to analyze our fMRI data. We followed the method outlined by Boynton and colleagues $(45,46)$ and divided our analysis into two independent steps. First, we located the activated picture elements or voxels. A motion correction using the automated image registration (47) was applied. This was followed by an intensity normalization, which adjusted the mean of the data to a value of 1000 . Subsequently, a multilinear correction for baseline drift was applied. Activated voxels with either a positive or negative BOLD response were determined using a cross-correlation analysis. The activated voxels detected were then subjected to a Bonferroni correction to correct for multiple testing. The correction threshold was obtained by convolving the uncorrected threshold $(p=0.05)$ with the number of voxels in a mask restricting the correction to the subject's head. The number of activated voxels remaining after this correction was taken as the extent of activation. We then used the $\mathrm{x}, \mathrm{y}$, and $\mathrm{z}$ coordinates of each activated voxels to extract the time series.

We determined the change in the $\mathrm{CMRO}_{2}$ by examining the change in the $\mathrm{HbR}$ concentration using $\Delta \mathrm{R} 2 *$ as an indicator (30). The $\Delta \mathrm{R} 2 *$ was calculated by comparing the transverse magnetization signal at each time point against that of the baseline, using the formula

$$
\Delta \mathrm{R} 2 *=(-1 / \mathrm{TE}) \times \ln \left(\mathrm{S}_{\mathrm{t}} / \mathrm{S}_{\mathrm{b}}\right) .
$$

We defined our baseline signal $\left(\mathrm{S}_{\mathrm{b}}\right)$ as the average of the 10 control scans of the first cycle. Where TE is the echo time, $S_{t}$ the MR signal at a specific time point, and $\mathrm{S}_{\mathrm{b}}$ the baseline MR signal (28). A $\Delta \mathrm{R} 2 *$ of 0 indicates no change in the $\mathrm{HbR}$ concentration compared with the baseline. A positive $\Delta \mathrm{R} 2 *$ is associated with a negative BOLD response and indicates an increase in the concentration of $\mathrm{HbR}$ compared with the baseline. A negative $\Delta \mathrm{R} 2 *$ is associated with a positive BOLD response and indicates a decrease in the concentration of $\mathrm{HbR}$ compared with the baseline. $\Delta \mathrm{R} 2 *$ is proportional to the change in $\mathrm{HbR}$ concentration from the baseline.

\section{RESULTS}

We pooled the luminance and chromatic contrast data as the BOLD responses to the luminance and chromatic contrast stimuli which have been reported to be the same (48). Figure $2 A$ shows the location of the activated voxels overlayed onto an anatomical image of a child from the younger age group. Figure $2 B$ shows the activated voxels in a child from the older age group. In both cases, activated voxels were located in the striate cortex.
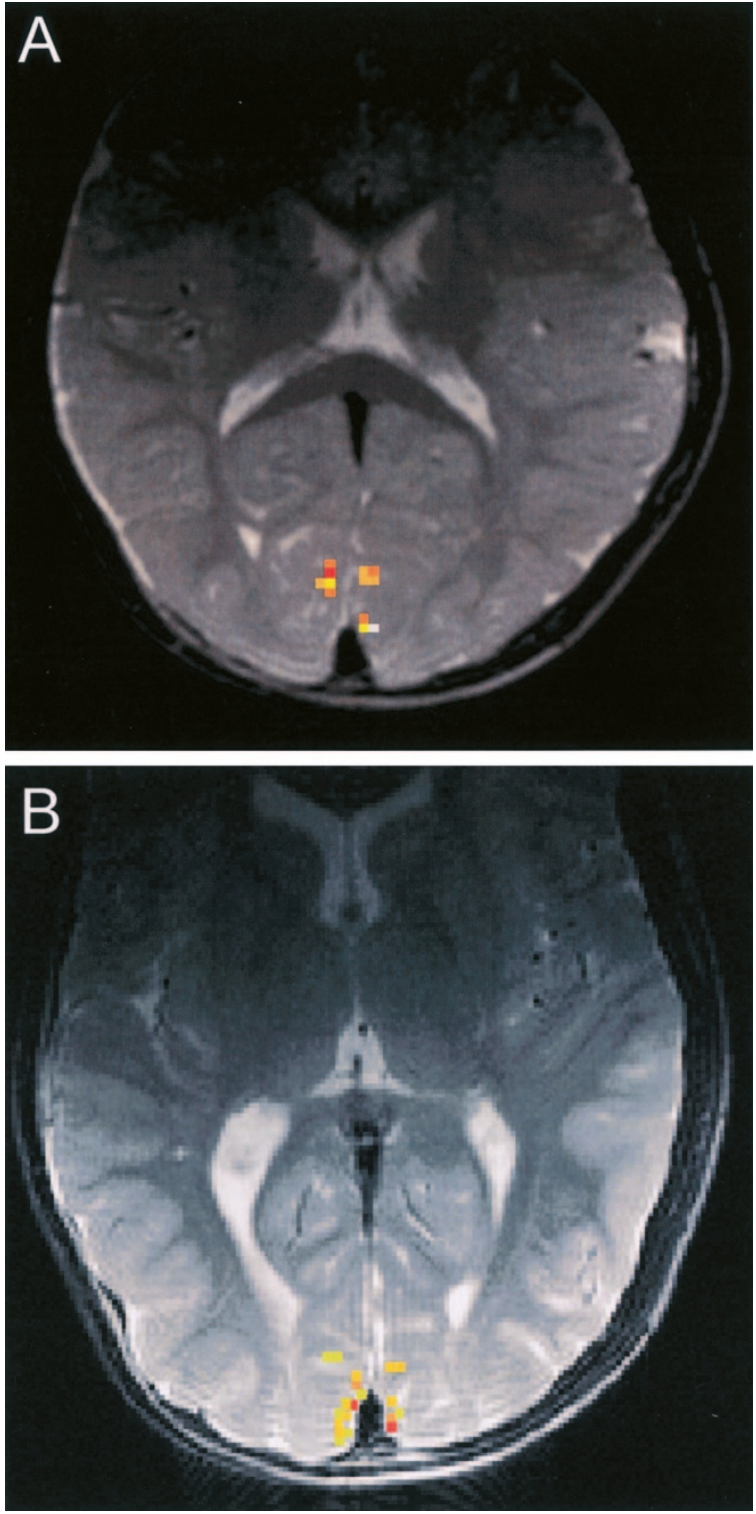

Figure 2. (A) Location of the activated voxels to the flashed, chromatic contrast checkerboard in one of the children in the younger age group. $(B)$ Location of the activated voxels to the same stimulus in one of the five children of the older age group measured under anesthesia. In both cases, the activated voxels area clearly located in visual cortex.

All statistical analyses were performed using SPSS Version 11.5 (SPSS Inc., Chicago, IL). The data were analyzed using repeated measures of the general linear model with age as the between-subject factor and stimulus type as the repeated measures factor. As is standard practice we will only provide details of the statistical results that attained significance $(p \leq$ $0.05)$.

In a separate study examining the influence of light Sevoflurane anesthesia on the BOLD response, we found that the extent of activation was attenuated under anesthesia but that the $\mathrm{CMRO}_{2}$ and the $\mathrm{CBF}$ response were unaltered. We therefore excluded the five children measured awake from the analysis of the extent of activation because their inclusion would have introduced a confounding effect between the age group and the use of an anesthetic agent. These five children 
were included in the analysis of $\Delta \mathrm{R} 2 *$, as our previous study had shown $\Delta \mathrm{R} 2 *$ to be unaffected by the anesthetic agent.

Extent of activation of the positive $B O L D$ response. Figure $3 A$ shows the mean number of activated voxels with a positive BOLD response. There was no difference between the two age groups.

Extent of activation of the negative $B O L D$ response. Figure $3 B$ shows the mean number of activated voxels with a negative BOLD response for the flashed and the reversing stimuli. There was no difference between the age groups.

$\mathrm{CMRO}_{2}$ and the positive $\mathrm{BOLD}$ response. With our flashed and reversing checkerboards, we were in a position to use $\Delta \mathrm{R} 2 *$ as an indicator of the change in the neuronal oxidative metabolism. Figure $4, A$ and $B$, shows $\Delta \mathrm{R} 2 *$ at each time point in a "time-locked" graph. Figure $4 A$ represents the data obtained from the younger children, and Figure $4 B$ shows the data from the older children. Figure $6 A$ shows the peak $\Delta \mathrm{R} 2 *$ values for the two stimuli in the two age groups. The error bars in the figures represent the SEM. We found a statistically significant difference in the peak $\Delta \mathrm{R} 2 *$ between the flashed and the reversing checkerboard $\left(\mathrm{F}_{\mathrm{Wilks}}=28.609 ; d f=1,18 ; p=\right.$ $\left.0.000 ; \mathrm{ETA}^{2}=0.614\right)$. We also found a significant interaction with the age $\left(\mathrm{F}_{\text {Wilks }}=4.705 ; d f=1,18 ; p=0.045\right.$; $\mathrm{ETA}^{2}=$ 0.207).
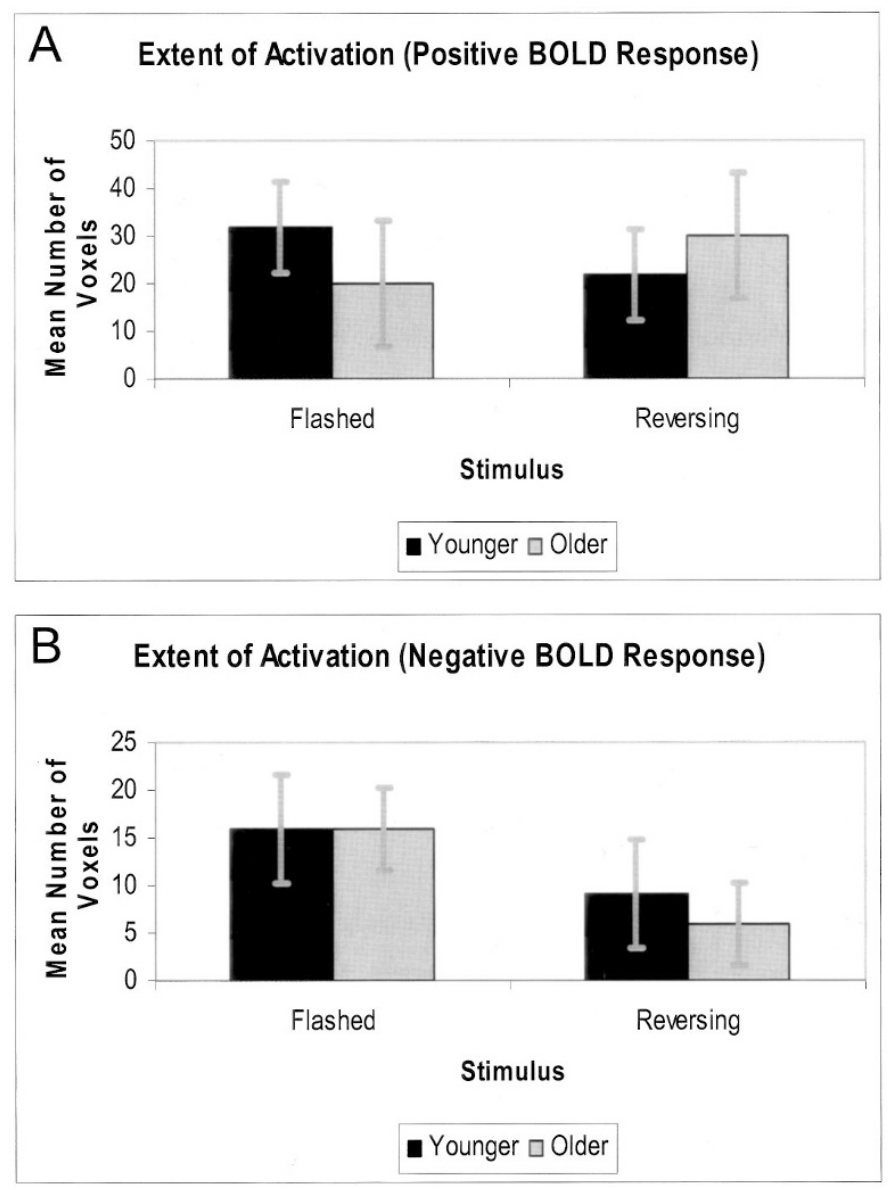

Figure 3. (A) Mean number of activated voxels with a positive BOLD response to the flashed and reversing checkerboard stimuli in the two age groups (younger, $\mathrm{n}=11$; older, $n=5$. (B) Data for the voxels with a negative BOLD response. The bars indicate the standard error of the mean.
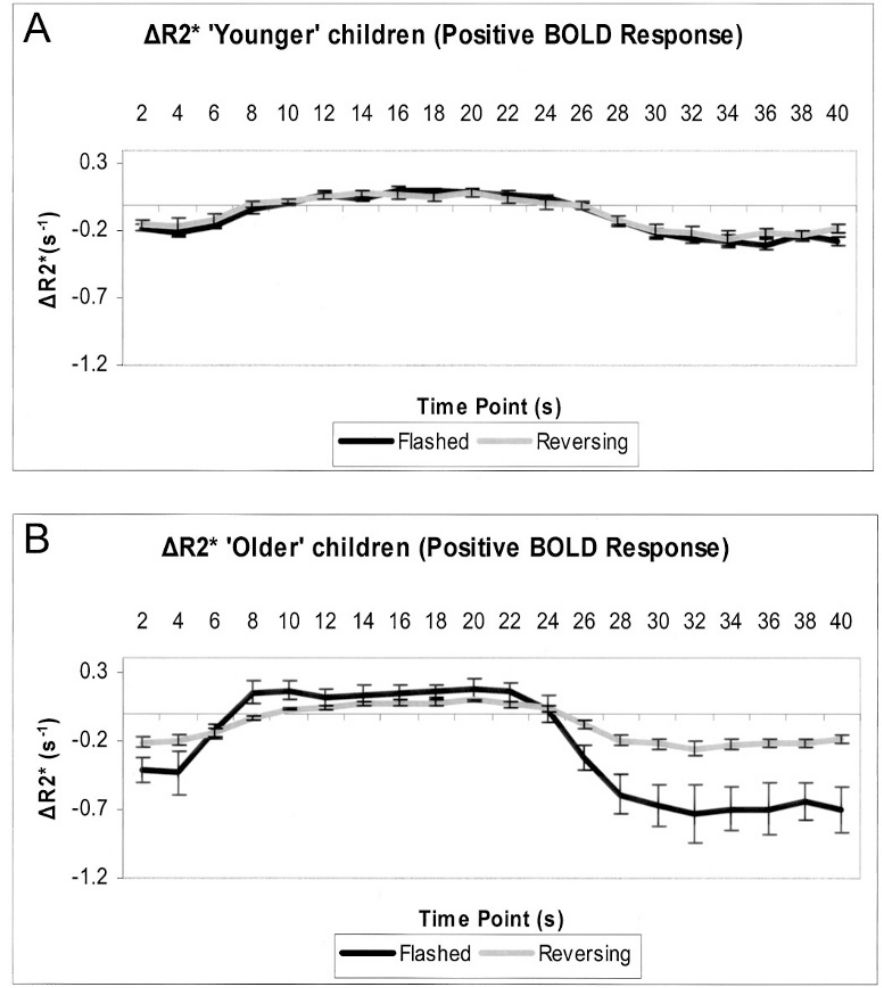

Figure 4. Peak $\Delta \mathrm{R} 2 *$ values obtained from the voxels with a positive BOLD signal. (A) Peak $\Delta \mathrm{R} 2 *$ for each "time-locked" time point to the flashed and reversing checkerboard stimulus from the children in the younger age group ( $n$ $=11)$. $(B)$ The same data for the children in the older age group $(n=5)$. The data from the flashed checkerboard is shown by the black curve, the data for the reversing checkerboard by the gray curve. The closer the $\Delta \mathrm{R} 2 *$ values are to 0 , the smaller the change in HbR concentration between that time point and the baseline. The bars indicate the standard error of the mean.

$\mathrm{CMRO}_{2}$ and the negative $\mathrm{BOLD}$ response. Figure 5, $A$ and $B$, shows "time-locked" graphs of the $\Delta \mathrm{R} 2 *$ at each time point. Figure $5 A$ represents the data obtained from children under $5 \mathrm{y}$ of age, whereas Figure $5 B$ shows the data from children older than $5 \mathrm{y}$. Figure $6 B$ shows the peak $\Delta \mathrm{R} 2 *$ values for the two stimuli in the two age groups. The error bars in the figures represent the SEM. We found no statistically significant difference in the peak $\triangle \mathrm{R} 2 *$ from the voxels with a negative BOLD response.

\section{DISCUSSION}

Our study has shown that the BOLD signal response in young children is markedly different from that seen in older children. In older children, as in adults, the BOLD signal amplitude to the flashed checkerboard resulted in a larger BOLD signal amplitude than the reversing checkerboard. In the younger children, the BOLD signal amplitude to both stimuli corresponded to the amplitude observed with the reversing checkerboard stimulus in the older children. In this section we will examine the possible reasons for this difference in the BOLD response between the two age groups. This will include an examination of the origin of the BOLD signal, a discussion on the relationship between neuronal activity and $\mathrm{CMRO}_{2}$, and examination of the relationship between the BOLD signal and the OEF. 

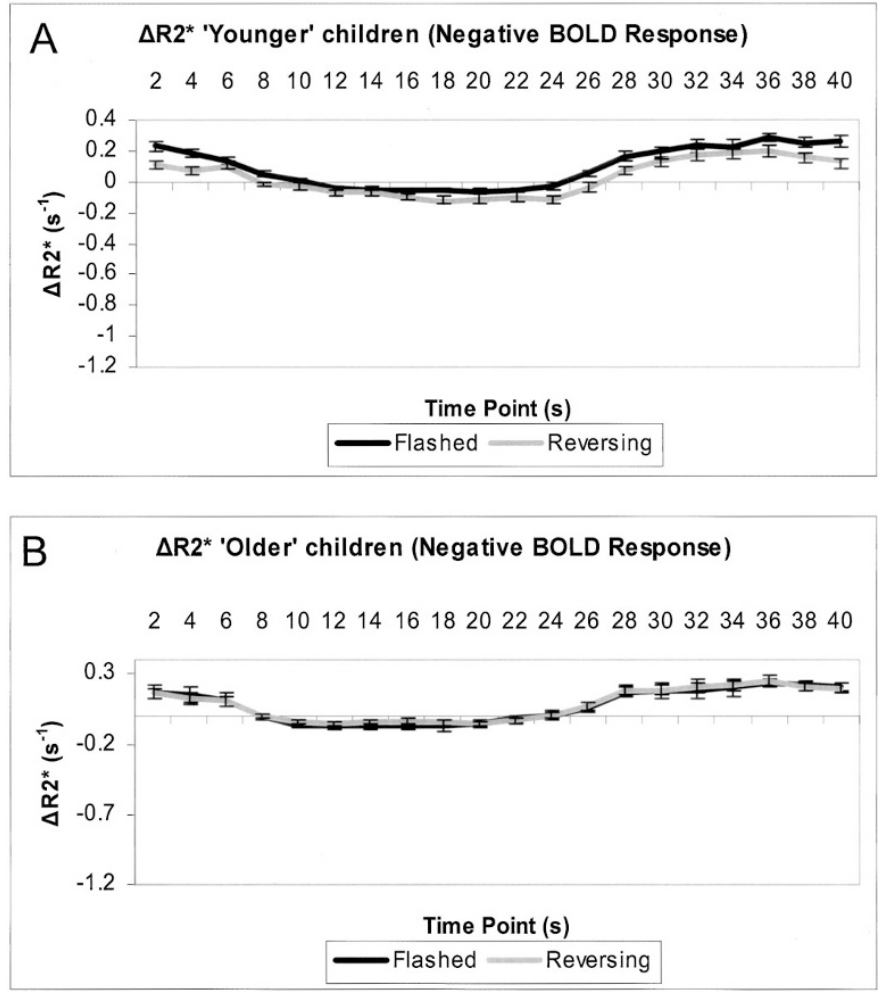

Figure 5. $\Delta \mathrm{R} 2 *$ values obtained from the voxels with a negative BOLD signal. (A) Peak $\Delta \mathrm{R} 2 *$ for each "time-locked" time point to the flashed and reversing checkerboard stimulus from the children in the younger age group. $(B)$ The same data for the children in the older age group. The data from the flashed checkerboard is shown by the black curve, the data for the reversing checkerboard by the gray curve. The closer the $\Delta \mathrm{R} 2 *$ values are to 0 , the smaller the change in $\mathrm{HbR}$ concentration between that time point and the baseline. The bars indicate the SEM.

The origin of the BOLD signal. The BOLD signal is used by virtually all functional MRI studies and is the result of a local change in the HbR concentration. An increase in neuronal activity leads to an increase in the local $\mathrm{CMRO}_{2}$. This in turn leads to more of the oxyhemoglobin $(\mathrm{HbO})$ being turned into $\mathrm{HbR}$. The diamagnetic property of $\mathrm{HbO}$ renders it invisible to MR imaging. The paramagnetic property of $\mathrm{HbR}$ on the other hand decreases the MR signal. A local increase in neuronal activity is generally believed to be followed by a local increase in blood flow (CBF). This vascular response dilutes the local HbR concentration to such an extent that the MR signal increases during neuronal activation compared with rest. This is what is commonly referred to as the BOLD response.

Defining neuronal activation. Traditionally, neuronal activity has been synonymous with electrical discharge activity. Functional MRI using the BOLD response is based on detecting changes in the $\mathrm{HbR}$ concentration in a brain volume as small as $1 \mathrm{~mm}^{3}$. A volume of this size contains millions of cells. The $\mathrm{CMRO}_{2}$ and consequently the $\mathrm{HbR}$ concentration within this small volume will depend not only on the electrical discharge activity, but also, and probably more so, on the number of activated cells. In our investigation we manipulated the size of the activated neuronal population while keeping their electrical activity constant.

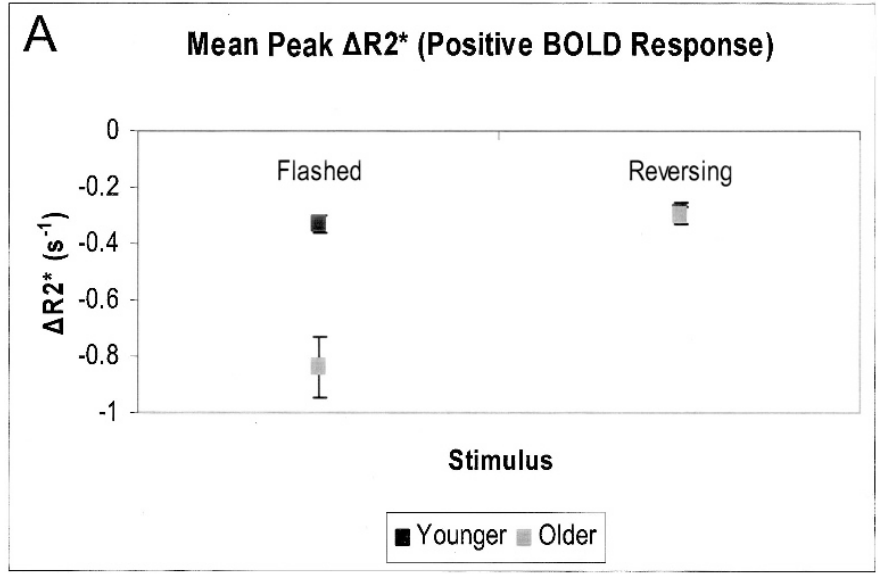

\section{B Mean Peak $\Delta \mathbf{R 2}^{*}$ (Negative BOLD Response)}

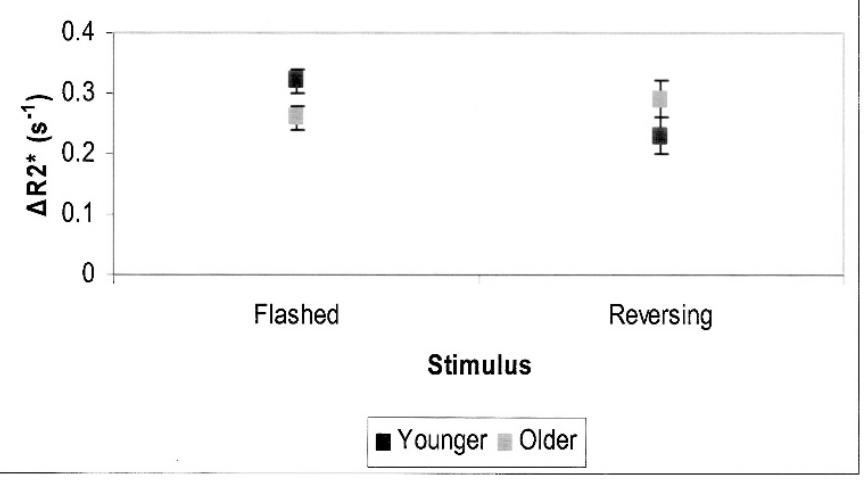

Figure 6. Peak $\Delta \mathrm{R} 2 *$ for the flashed and the reversing checkerboard stimuli (A) Peak $\Delta \mathrm{R} 2 *$ from the pixels with a positive BOLD signal. The data from the younger children $(n=11)$ are shown in black, the data from the older children $(n=5)$ in gray. The closer the $\Delta \mathrm{R} 2 *$ values are to 0 , the smaller the change in $\mathrm{HbR}$ concentration compared with the baseline. $(B)$ Data from the pixels with a negative BOLD signal. In $A$ and $B$, the data from the younger children are shown in black, the data from the older children in gray. The closer the $\Delta \mathrm{R} 2 *$ values are to 0 , the smaller the change in HbR concentration compared with the baseline. The bars indicate the standard error of the mean.

The effect of our stimuli on CBF. We did not actually measure the $\mathrm{CBF}$ response using blood flow- or perfusionsensitive MR sequences such as arterial spin labeling. A recent study has reported that the measurement of the CBF response using arterial spin labeling is not as reliable as that obtained by PET (49). Measuring the CBF response to our stimuli would have more than doubled the time the child had to be kept under anesthesia or the child would have to be subjected to a PET measurement. We relied instead on the published PET data of Fox and Raichle (25), demonstrating that the CBF response to a flashed and a reversing stimulus is identical. The finding of our study of a larger $\Delta \mathrm{R} 2 *$ for the flashed when compared to the reversing checkerboard is consistent with the prediction by Buxton (50) for stimuli with identical CBF responses but differing $\mathrm{CMRO}_{2}$. These observations, taken together, confirm that our checkerboard stimuli did induce identical CBF responses.

Effect of our stimuli on neuronal oxidative metabolism $\left(\mathrm{CMRO}_{2}\right)$. For reasons discussed by Marcar and colleagues (26), the number of activated neurons and the mean electrical 
activity resulting from the presentation of the reversing checkerboard was double that resulting from the presentation of the flashed checkerboard. Doubling the size of the activated neuronal population will also double the $\mathrm{CMRO}_{2}$. Both checkerboard stimuli induced identical vascular responses so that doubling the $\mathrm{CMRO}_{2}$ implies that more oxygen has to be extracted from the blood, thus increasing the OEF. Increasing the OEF will result in an elevation of the local HbR concentration.

Influence of anesthesia on the BOLD response. The effect of performing fMRI measurements on children during sleep, be it natural $(16,17)$ or induced $(18,51)$, is well documented. In studies where sleep was induced, a sedative agent was used. The administration of a sedative agent has been found to reduce glucose metabolism $\left(\mathrm{CMR}_{\mathrm{Glc}}\right)$ by $25-30 \%$ (52) and results in a reduction of the BOLD response (51). What effect measuring children under light anesthesia has on the BOLD signal is unknown. The influence of light anesthesia on $\mathrm{CMRO}_{2}$ and its implication for BOLD measurements are reported in our companion paper (53). In summary, we found that sevoflurane anaesthesia attenuated the extent of activation, whereas its effect on $\mathrm{CBF}$ and $\mathrm{CMRO}_{2}$ were found to be minimal (53).

Effect of cortical maturation on CBF. As mentioned above, our study did not include a measurement of the CBF response. Instead, we drew on PET measurements in adults to assess the CBF response to our flashed and reversing checkerboards. The hemodynamic response to a neuronal challenge has also been found to be the same in children younger than $5 \mathrm{y}$ of age compared with children older than $5 \mathrm{y}$ of age $(15,23,24)$. These studies clearly indicate that the CBF response does not vary between younger and older children. Maturational changes in CBF show a similar time course as the maturational changes in $\mathrm{CMR}_{\mathrm{Glc}}$ (54,55). A tight coupling between the baseline CM$\mathrm{R}_{\mathrm{Glc}}$ and CBF exists throughout cerebral development (56) and adulthood (57). These studies indicate that the observed difference in the BOLD response between the two age groups is not the result of a change in the vascular response with age. Having excluded a maturational effect on the vascular response as a cause of our observed result, the most likely reason for the observed difference in the BOLD signal amplitude is a change in the oxidative metabolism $\left(\mathrm{CMRO}_{2}\right)$ with age.

Effect of cortical maturation on $\mathrm{CMRO}_{2}$. A change in the oxidative metabolism is likely to result from a change in the number of cells being activated or in the number of synapses. Both neuronal density and synaptic density are subject to a significant change with age. The ratio of gray to white matter is larger in young children than adults (58). This implies that the brains of young children will have a higher metabolic requirement simply because their brains contain more neurons. Anatomical studies indicate that the neuronal density reaches its peak at the time of birth. It is unlikely that a maturational change in $\mathrm{CMRO}_{2}$ is the result of a change in neuronal density. The more likely cause is a change in synaptic density with age. An assessment of the energy expenditure of neurons revealed that the majority of the energy is expended at the synapses (59-61). Synaptic density has been found to peak between 4 and $7 \mathrm{y}$ of age $(62,63)$. A PET study has shown that $\mathrm{CMR}_{\mathrm{Gluc}}$ increases up to $5 \mathrm{y}$ and then declines (56). These are indications that the neuronal metabolic activity that is higher in young children is perhaps due to a higher synaptic density.

Effect of $\mathrm{CMRO}_{2}$ on the BOLD signal. We have already presented our arguments relating to the influence of our stimuli on the BOLD signal. In this section, we examine the influence of a change in neuronal density compared with a change in synaptic density on the BOLD signal. A higher neuronal density elevates the baseline metabolic activity and thereby reduces the dynamic range of the BOLD signal. A higher neuronal density, however, would not alter the relative difference in $\mathrm{CMRO}_{2}$ between our flashed and the reversing checkerboard stimuli. The BOLD signal in all age groups should therefore reflect this relative difference in $\mathrm{CMRO}_{2}$. The maturational change in synaptic density is not the result of a change in the number of neurons but the result of a change in the number of synaptic connections between them. Changing synaptic density has little effect on the baseline $\mathrm{CMRO}_{2}$ but has a strong effect on the $\mathrm{CMRO}_{2}$ associated with neuronal activity. An immature visual system containing many superfluous neuronal connections will be less energy efficient than a mature visual system. This reduced energy efficiency will manifest itself more strongly during neuronal activation. A change in synaptic density will not alter the baseline $\mathrm{CMRO}_{2}$ and so has little influence on the dynamic range of the BOLD signal. The presence of superfluous neuronal connections raises $\mathrm{CMRO}_{2}$ during neuronal activity because more neurons than actually required will be activated by a given stimulus, making the system less energy efficient. A high $\mathrm{CMRO}_{2}$ level during neuronal activity implies a high OEF, a high HbR concentration, and an attenuation of the BOLD signal amplitude.

\section{CONCLUSIONS}

Our study set out to investigate the hypotheses put forward by Gaillard and colleagues (64), by examining whether the immature nervous system leads to a more diffuse BOLD response or to a lower BOLD amplitude and less activation. The results of our study indicate that the BOLD response in young children is most strongly influenced by $\mathrm{CMRO}_{2}$. As a result of the reduced energy efficiency of the immature nervous system, the local OEF and the HbR concentration are higher. The BOLD signal amplitude in response to neuronal activation will tend to be smaller in young children compared with older children or adults. A lower BOLD signal amplitude makes it more difficult to detect neuronal activation using statistical methods. Only when the superfluous connections and members of a network of neurons are pruned, does the energy efficiency improve and the metabolic cost of neuronal processes decline. A decline in $\mathrm{CMRO}_{2}$ reduces the OEF and the local $\mathrm{HbR}$ concentration. This in turn increases the BOLD signal amplitude which makes it easier to detect neuronal activation.

\section{REFERENCES}

1. Fantz RL 1965 Visual perception from birth as shown by pattern selectivity. Ann N Y Acad Sci 118:793-814

2. Bronson G 1974 The postnatal growth of visual capacity. Child Dev 45:873-890

3. Atkinson J 1984 Human visual development over the first 6 months of life. A review and a hypothesis. Hum Neurobiol 3:61-74 
4. Lengyel D, Weinacht S, Charlier J, Gottlob I 1998 The development of visual pursuit during the first months of life. Graefes Arch Clin Exp Ophthalmol 236:440-444

5. Weinacht S, Kind C, Monting JS, Gottlob I 1999 Visual development in preterm and full-term infants: a prospective masked study. Invest Ophthalmol Vis Sci 40:346-353

6. Blakemore C, Vital-Durand F 1986 Organization and post-natal development of the monkey's lateral geniculate nucleus. J Physiol 380:453-491

7. Mates SL, Lund JS 1983 Developmental changes in the relationship between type 2 synapses and spiny neurons in the monkey visual cortex. J Comp Neurol 221:98-105

8. Hubel DH, Wiesel TN 1968 Receptive fields and functional architecture of monkey striate cortex. J Physiol 195:215-243

9. Van Essen DC 1979 Visual areas of the mammalian cerebral cortex. Annu Rev Neurosci 2:227-263

10. DeYoe EA, Carman GJ, Bandettini P, Glickman S, Wieser J, Cox R, Miller D, Neitz J 1996 Mapping striate and extrastriate visual areas in human cerebral cortex. Proc Natl Acad Sci U S A 93:2382-2386

11. Dehaene-Lambertz G, Dehaene S, Hertz-Pannier L 2002 Functional neuroimaging of speech perception in infants. Science 298:2013-2015

12. Gaillard WD, Sachs BC, Whitnah JR, Ahmad Z, Balsamo LM, Petrella JR, Braniecki SH, McKinney CM, Hunter K, Xu B, Grandin CB 2003 Developmental aspects of language processing: fMRI of verbal fluency in children and adults. Hum Brain Mapp 18:176-185

13. Hertz-Pannier L 1999 [Brain plasticity during development: physiological bases and functional MRI approach]. J Neuroradiol 26:S66-S74

14. Hertz-Pannier L, Chiron C, Vera P, Van de Morteele PF, Kaminska A, Bourgeois M, Hollo A, Ville D, Cieuta C, Dulac O, Brunelle F, LeBihan D 2001 Functional imaging in the work-up of childhood epilepsy. Childs Nerv Syst 17:223-228

15. Souweidane MM, Kim KH, McDowall R, Ruge MI, Lis E, Krol G, Hirsch J 1999 Brain mapping in sedated infants and young children with passive-functional magnetic resonance imaging. Pediatr Neurosurg 30:86-92

16. Born P, Rostrup E, Leth H, Peitersen B, Lou HC 1996 Change of visually induced cortical activation patterns during development. Lancet 347:543

17. Born AP, Miranda MJ, Rostrup E, Toft PB, Peitersen B, Larsson HB, Lou HC 2000 Functional magnetic resonance imaging of the normal and abnormal visual system in early life. Neuropediatrics 31:24-32

18. Martin E, Joeri P, Loenneker T, Ekatodramis D, Vitacco D, Hennig J, Marcar VL 1999 Visual processing in infants and children studied using functional MRI. Pediatr Res 46:135-140

19. Martin E, Marcar VL 2001 Functional MR imaging in pediatrics. Magn Reson Imaging Clin N Am 9:231-246

20. Muramoto S, Yamada H, Sadato N, Kimura H, Konishi Y, Kimura K, Tanaka M Kochiyama T, Yonekura Y, Ito H 2002 Age-dependent change in metabolic response to photic stimulation of the primary visual cortex in infants: functional magnetic resonance imaging study. J Comput Assist Tomogr 26:894-901

21. Yamada H, Sadato N, Konishi Y, Kimura K, Tanaka M, Yonekura Y, Ishii Y 1997 A rapid brain metabolic change in infants detected by fMRI. Neuroreport 8:37753778

22. Gaillard WD, Grandin CB, Xu B 2001 Developmental aspects of pediatric fMRI considerations for image acquisition, analysis, and interpretation. Neuroimage 13:239-249

23. Logan WJ 1999 Functional magnetic resonance imaging in children. Semin Pediat Neurol 6:78-86

24. Stapleton SR, Kiriakopoulos E, Mikulis D, Drake JM, Hoffman HJ, Humphreys R, Hwang P, Otsubo H, Holowka S, Logan W, Rutka JT 1997 Combined utility of functional MRI, cortical mapping, and frameless stereotaxy in the resection of lesions in eloquent areas of brain in children. Pediatr Neurosurg 26:68-82

25. Fox PT, Raichle ME 1985 Stimulus rate determines regional brain blood flow in striate cortex. Ann Neurol 17:303-305

26. Marcar VL, Strässle A, Loenneker T, Girard F, Martin E 2004 When more mean less: a paradox BOLD response in human visual cortex. Magn Reson Imaging 22:441-450

27. Hoge RD, Atkinson J, Gill B, Crelier GR, Marrett S, Pike GB 1999 Investigation of BOLD signal dependence on cerebral blood flow and oxygen consumption: the deoxyhemoglobin dilution model. Magn Reson Med 42:849-863

28. Kim SG, Rostrup E, Larsson HB, Ogawa S, Paulson OB 1999 Determination of relative $\mathrm{CMRO}_{2}$ from $\mathrm{CBF}$ and BOLD changes: significant increase of oxygen consumption rate during visual stimulation. Magn Reson Med 41:1152-1161

29. Goodyear BG, Menon RS 1998 Effect of luminance contrast on BOLD fMRI response in human primary visual areas. J Neurophysiol 79:2204-2207

30. Ogawa S, Menon RS, Tank DW, Kim SG, Merkle H, Ellermann JM, Ugurbil K 1993 Functional brain mapping by blood oxygenation level-dependent contrast magnetic resonance imaging. A comparison of signal characteristics with a biophysical model. Biophys J 64:803-812

31. Schwarzbauer C, Heinke W 1999 Investigating the dependence of BOLD contrast on oxidative metabolism. Magn Reson Med 41:537-543

32. Dekaban AS 1978 Changes in brain weights during the span of human life: relation of brain weights to body heights and body weights. Ann Neurol 4:345-356

33. deJong R, Eger EI 1975 AD50 and AD95 values of common inhalation anaesthetics on man. Anesthesiology 42:384-389

34. Eger II EI, Saidman LJ, Brandstater B 1965 Minimum alveolar anesthetic concentration: a standard of anesthetic potency. Anesthesiology 26:756-763
35. Saidman LJ, Eger II EI, Munson ES, Babad AA, Muallem M 1967 Minimum alveolar concentrations of methoxyflurane, halothane, ether and cyclopropane in man: correlation with theories of anesthesia. Anesthesiology 28:994-1002

36. Fox PT, Raichle ME 1984 Stimulus rate dependence of regional cerebral blood flow in human striate cortex, demonstrated by positron emission tomography. J Neurophysiol 51:1109-1120

37. Hagenbeek RE, Rombouts SA, van Dijk BW, Barkhof F 2002 Determination of individual stimulus-response curves in the visual cortex. Hum Brain Mapp 17:244250

38. Vafaee MS, Gjedde A 2000 Model of blood-brain transfer of oxygen explains nonlinear flow-metabolism coupling during stimulation of visual cortex. J Cereb Blood Flow Metab 20:747-754

39. Vafaee MS, Meyer E, Marrett S, Paus T, Evans AC, Gjedde A 1999 Frequencydependent changes in cerebral metabolic rate of oxygen during activation of human visual cortex. J Cereb Blood Flow Metab 19:272-277

40. Boothe RG 1982 Optical and neural factors limiting acuity development: evidence obtained from a monkey model. Curr Eye Res 2:211-215

41. Fiorentini A, Trimarchi C 1992 Development of temporal properties of pattern electroretinogram and visual evoked potentials in infants. Vision Res 32:1609-1621

42. Madrid M, Crognale MA 2000 Long-term maturation of visual pathways. Vis Neurosci 17:831-837

43. Tootle JS, Friedlander MJ 1989 Postnatal development of the spatial contrast sensitivity of X-and Y-cells in the kitten retinogeniculate pathway. J Neurosci 9:13251340

44. Zumbroich T, Price DJ, Blakemore C 1988 Development of spatial and temporal selectivity in the suprasylvian visual cortex of the cat. J Neurosci 8:2713-2728

45. Boynton GM, Engel SA, Glover GH, Heeger DJ 1996 Linear systems analysis of functional magnetic resonance imaging in human V1. J Neurosci 16:4207-4221

46. Boynton GM, Demb JB, Glover GH, Heeger DJ 1999 Neuronal basis of contrast discrimination. Vision Res 39:257-269

47. Woods RP, Cherry SR, Mazziotta JC 1992 Rapid automated algorithm for aligning and reslicing PET images. J Comput Assist Tomogr 16:620-633

48. Bandettini PA, Kwong KK, Davis TL, Tootell RB, Wong EC, Fox PT, Belliveau JW, Weisskoff RM, Rosen BR 1997 Characterization of cerebral blood oxygenation and flow changes during prolonged brain activation. Hum Brain Mapp 5:93-109

49. Carroll TJ, Teneggi V, Jobin M, Squassante L, Treyer V, Hany TF, Burger C, Wang L, Bye A, Von Schulthess GK, Buck A 2002 Absolute quantification of cerebral blood flow with magnetic resonance, reproducibility of the method, and comparison with $\mathrm{H} 2(15) \mathrm{O}$ positron emission tomography. J Cereb Blood Flow Metab 22:11491156

50. Buxton RB 2002 Introduction to Functional Magnetic Resonance Imaging. Principles and Techniques. Cambridge University Press, Cambridge

51. Martin E, Thiel T, Joeri P, Loenneker T, Ekatodramis D, Huisman T, Hennig J, Marcar VL 2000 Effect of pentobarbital on visual processing in man. Hum Brain Mapp 10:132-139

52. Theodore WH 1989 The role of fluorodeoxyglucose-positron emission tomography in the evaluation of seizure disorders. Semin Neurol 9:301-306

53. Marcar VL, Loenneker T, Strässle A, Schwarz U, Gerber A, Martin E 2004 What effect does testing children under anesthesia have on the BOLD response? An fMRI study of visual cortex. Pediatr Res 56:104-110

54. Chiron C, Raynaud C, Maziere B, Zilbovicius M, Laflamme L, Masure MC, Dulac O, Bourguignon M, Syrota A 1992 Changes in regional cerebral blood flow during brain maturation in children and adolescents. J Nucl Med 33:696-703

55. Barthel H, Wiener M, Dannenberg C, Bettin S, Sattler B, Knapp WH 1997 Agespecific cerebral perfusion in 4- to 15-year-old children: a high-resolution brain SPET study using 99mTc-ECD. Eur J Nucl Med 24:1245-1252

56. Chugani HT 1987 Positron emission tomography: principles and applications in pediatrics. Mead Johnson Symp Perinat Dev Med 25:15-18

57. Fox PT, Raichle ME, Mintun MA, Dence C 1988 Nonoxidative glucose consumption during focal physiologic neural activity. Science 241:462-464

58. Giedd JN, Blumenthal J, Jeffries NO, Castellanos FX, Liu H, Zijdenbos A, Paus T, Evans AC, Rapoport JL 1999 Brain development during childhood and adolescence: a longitudinal MRI study. Nat Neurosci 2:861-863

59. Attwell D, Iadecola C 2002 The neural basis of functional brain imaging signals Trends Neurosci 25:621-625

60. Mata M, Fink DJ, Gainer H, Smith CB, Davidsen L, Savaki H, Schwartz WJ, Sokoloff L 1980 Activity-dependent energy metabolism in rat posterior pituitary primarily reflects sodium pump activity. J Neurochem 34:213-215

61. Schwartz WJ, Smith CB, Davidsen L, Savaki H, Sokoloff L, Mata M, Fink DJ, Gaine H 1979 Metabolic mapping of functional activity in the hypothalamoneurohypophysial system of the rat. Science 205:723-725

62. Huttenlocher PR, de Courten C, Garey LJ, Van der Loos H 1982 Synaptogenesis in human visual cortex-evidence for synapse elimination during normal development Neurosci Lett 33:247-252

63. Goldman-Rakic PS 1987 Development of cortical circuitry and cognitive function. Child Dev 58:601-622

64. Gaillard WD, Hertz-Pannier L, Mott SH, Barnett AS, LeBihan D, Theodore WH 2000 Functional anatomy of cognitive development: fMRI of verbal fluency in children and adults. Neurology 54:180-185 